\title{
Correction to: Genetic and clinical characterization of $B R C A$-associated hereditary breast and ovarian cancer in Navarra (Spain)
}

Ainara Ruiz de Sabando ${ }^{1,2,3}$, Edurne Urrutia Lafuente ${ }^{1,2}$, Fermín García-Amigot ${ }^{1,3}$, Angel Alonso Sánchez ${ }^{1,2,3}$, Lourdes Morales Garofalo", Sira Moreno ${ }^{1}$, Eva Ardanaz ${ }^{3,4,5}$ and Maria A. Ramos-Arroyo ${ }^{1,3^{*}}$

\section{Correction to: BMC Cancer (2019) 19:1145 https://doi.org/10.1186/s12885-019-6277-x}

Following publication of the original article [1], the authors reported an error in Fig. 2, where the color code of the text boxes is reversed. Figure 2-amended shows the correct color association between the text boxes and the different areas in the map: Navarra, neighbouring communities and other Spanish communities.

\section{Author details}

'Department of Medical Genetics, Complejo Hospitalario de Navarra (CHN), Pamplona, Spain. ${ }^{2}$ Navarrabiomed, Pamplona, Spain. ${ }^{3}$ IdiSNA, Navarra Institute for Health Research, Pamplona, Spain. ${ }^{4}$ Navarra Public Health Institute, Pamplona, Spain. ${ }^{5} \mathrm{CIBER}$ Epidemiology and Public Health CIBERESP, Madrid, Spain

Published online: 17 December 2019

\section{Reference}

1. de Sabando R, et al. Genetic and clinical characterization of BRCA-associated hereditary breast and ovarian cancer in Navarra (Spain). BMC Cancer. 2019; 19:1145. https://doi.org/10.1186/s12885-019-6277-X.

The original article can be found online at https://doi.org/10.1186/s12885019-6277-x

* Correspondence: ma.ramos.arroyo@navarra.es

'Department of Medical Genetics, Complejo Hospitalario de Navarra (CHN), Pamplona, Spain

${ }^{3}$ IdiSNA, Navarra Institute for Health Research, Pamplona, Spain

Full list of author information is available at the end of the article

(c) The Author(s). 2019 Open Access This article is distributed under the terms of the Creative Commons Attribution 4.0 International License (http://creativecommons.org/licenses/by/4.0/), which permits unrestricted use, distribution, and reproduction in any medium, provided you give appropriate credit to the original author(s) and the source, provide a link to the Creative Commons license, and indicate if changes were made. The Creative Commons Public Domain Dedication waiver (http://creativecommons.org/publicdomain/zero/1.0/) applies to the data made available in this article, unless otherwise stated. 


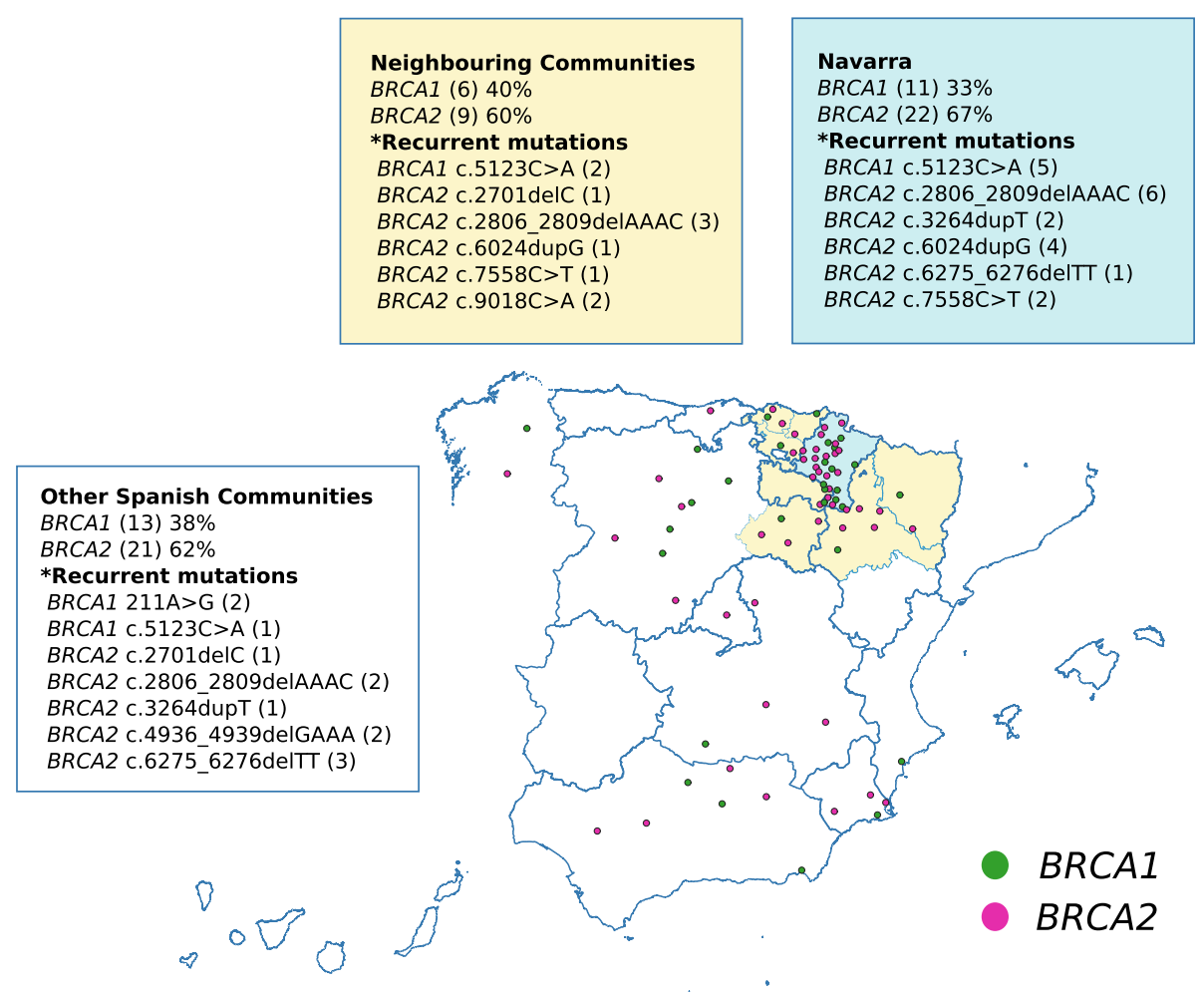

Fig. 2 Geographical origin of the hereditary breast/ovarian cancer families in Navarra. (Map created with QGIS 3.0) 